Journal of Life Economics

Cilt / Volume 7, Say1 / Issue 4, 2020, pp. 361-372

E - ISSN: 2148-4139

URL: https://www.journals.gen.tr/jlecon

DOİ: https://doi.org/10.15637/jlecon.7.027

Araştırma Makalesi/Research Article

\title{
THE RESTRUCTURING OF THE ADMINISTRATIONAL- ORGANISATIONAL APPROACHES OF BUSINESSES IN THE PROCESS OF INDUSTRY 4.0
}

\author{
Naci Atalay DAVUTOĞLU* \\ * Lect., Erciyes University, Vocational School of Social Sciences, Management, \\ TURKEY, e-mail: davuta@erciyes.edu.tr \\ ORCID: https://orcid.org/0000-0003-4881-8242
}

Received: 30 April 2020; Accepted: 10 October 2020

\begin{abstract}
Industrial revolutions have long since been mandatory for humanity in order to adapt to the age and innovations, resulting in the search of new ways to sustain productivity. Regardless of the line of business or the historical background of a sector, the concept of industrial revolution underlies the historical development of all sectors. The main reason is that production sustainability occurs when humanity presents their products at the same time announcing them. Consequently, new ideas, creations and revolutions can develop. Based on this, the first Industrial Revolution developed as a direct result of mechanisation while the Second Industrial Revolution developed as a result of electricity, and the Third Industrial Revolution developed as a direct result of computerisation.

Nowadays, the Fourth Industrial Revolution aims to transform Internet of Things and Internet of Services into production. In the near future, enterprises will adapt to these innovations and hence improve their technologies, managerial and organisational perceptions, administrative levels, decisionmaking and logistic systems, as well as production facilities by means of developing global networks as part of Cyber-Physical Systems. Thanks to Cyber-Physical Systems, enterprises will carry out information production, control function, smart machines and storage systems independently within the production environment. This system will provide a rapid development of concepts like production, engineering, material procurement, industrial processes, supply chain, and life-cycle systems.

Therefore, the aim of the present study is to theoretically analyse how managerial and organisational perceptions of enterprises undergo changes following the adoption of Industry 4.0 using literature review, which is defined as second-hand data, and to discuss the issues considering the restructuring of management-organisation of enterprises in accordance with this developing trend.
\end{abstract}

Key Words: Industry 4.0, Management-Organisation, Cyber-Physical Systems, Internet of Things, Internet of Services.

Jel Codes: M10, M12, M13 


\section{INTRODUCTION}

In recent times, humanity has constantly been developing antitheses to ever-changing and ever-evolving technology, along with social, economic, environmental and climatic issues. These antitheses, in turn, have brought about new production systems, and administrationalorganisational structures suitable for these systems. Hence, they emphasise the organisational structures constructed in line with production systems based on technological devices that individually communicate with each other through the value chain.

In this process, which is called Industry 4.0, all business owners and administrators are required to improve appropriate information systems, physical opportunities and different technologies that adequately satisfy the needs of future economy by implementing this novelty to their businesses. Restructuring the products and services produced as a result of this development in accordance with the new process is possible only if the administrationalorganisational structure of the business and the traditional working conditions are transformed.

Nowadays, the Fourth Industrial Revolution aims to transform the Internet of Things and Services into production. In the near future, by undergoing a change thanks to Industry 4.0, businesses will improve their technological framework, administrational and organisational approaches, administrative levels, and decision making and production systems by means of forming global networks in the form of Cyber-Physical Systems. They will carry out information production, control function, smart machines and storage systems in their production environment independently of each other thanks to Cyber-Physical Systems. Through this system, concepts like production, engineering, procurement, industrial processes, supply chains, and lifecycle systems will rapidly improve.

In order for the businesses transformed by Industry 4.0 to prepare for the future, it is essential to identify priorities for the essentials of improvement and transformation required for the adaptation to the transformation, and present long-term effects of this transformation on labour. Additionally, they are required to enable business-to-business standardisation, identify new and practical business models, and, finally, to undergo anadministrational-organisational restructuringin accordance with the future vision, Industry 4.0, as a result of developing new technologies intended for analytical analysis via smart systems, and digital programs suitable for all the data and work principles of the business.

Moreover, they need to carry out systems integration of complex systems and manage them by cloud computing system, compile a digital infrastructure for the businesses in each sector, manage their own businesses and form new collaborations, present consumers with products that carry information, and maximise production and business performance. Finally yet importantly, they are required to master the business world and all other factories and businesses via the Internet of Things, and form a cybernetic security network without any vulnerability.

In order to design and create a business organisation suitable for the robotic technology of Industry 4.0, carry out smart production in smart factories, and professionalise the personnel, it is essential to carry out certain criteria, such as regular training sessions in information technologies, innovation, and promoting entrepreneurship, effective and efficient use of the business resources in line with systems integration, and cost reduction.

Taking these notions into consideration, the aim of the present study is to analyse via literature review, which is expressed as second-hand data, not only how administrationalorganisational approaches of businesses can be transformed by the adaptation of the concept of Industry 4.0 but also to investigate the restructuring of administrational-organisational approaches of businesses in line with the new trend. 


\section{The Concept and Scope of Industry 4.0}

Both the increasing usage ofInternet-related items in production and its effect on industrial processes have caused visionary countries and businesses to be inclined to new strategic discussions and directions. Despite the confusion experienced in the usage of the concepts, all the pioneering elements of the content attempt to form a completely different future by means of the effect of the world of the Internet on the world of machinery along with the new opportunities that will be created by this interaction (Kagermann, et al., 2013). The concept ofIndustry 4.0 is defined with an emphasis on the novelties created by the usage of the Internet in production (Brettel, et al., 2014).

The Fourth Industrial Revolution or Industry 4.0 will change especially the production processes of high-tech products and the products that require the Internet and mobile computers (Acatech, 2011). One the one hand, products can be produced in a smarter and more customized way; on the other hand, customer requirements will gradually diversify and increase, which will result in the shortening of product life cycle along with an increase in competition (Landscheidt \& Kans, 2016).

Industry 4.0 is a collective entity of technologies and value chain organisations. In general, it consists of three structures; namely, the Internet of Things, the Internet of Services, and Cyber-Physical Systems. In other words, smart factories constructed in line with the concept of Industry 4.0 and modular structures consist of monitoring physical systems with Cyber-Physical Systems, making a virtual copy of the physical word, and making decentralised decisions (Lee J., et al., 2015). In Industry 4.0, the Internet of Things and Cyber-Physical Systems will be able to collaborate and communicate in real-time with each other and people. By forming virtual organisations via the Internet of Services, it will be possible to provide both internal and cross-organisational services, and the users of value chains will be able to utilize them (TUSIAD, 2016).

Through Industry 4.0, there will be fundamental changes in industry with the increasing use of Internet-connected items in production. Moreover, there will be novelties in plenty of areas from business development to engineering subsequent to the usage of the Internet and artificial intelligence in the production of smart machines (Toker, 2016). The fact that Industry 4.0 has come to the forefront for the businesses in every sector firstly in industrial nations and later in other nations trying to catch up with this trend can be explained by means of the pace of technological change, innovative technologies, customized solution requirements, the increase in the market and customer diversity, cost reduction, globalisation, the significance of products availability and rapid delivery, along with the increase in energy costs and environmental awareness, production networks, flexibility and compatibility in production, autonomous and information-based systems (TUSIAD, 2016).

The main aim of Industry 4.0, which will be the vision for the businesses of the next century, is to combine information technologies and industry. Namely, contrary to today's conventional equipment, the equipment in Industry 4.0 is not only cost-efficient, compact, energy-efficient, and low in heat generation, but also operates with high levels of safety, and efficiently uses the sources and memory of the software and operation systems that run it.

Concisely, Industry 4.0 aims to create smart factories that are flexible, integrate customers and business partners, possess the ability to adapt to increasing product variety, and use the sources efficiently. These factories can establish advanced technology, communications and smart systems by connecting them to a network via the Internet and cloud computing system. If Industry 4.0 is implemented in these factories, production time, costs and energy will decrease, which, in turn, will result in an increased turnout and quality (EBSO, 2015).The 
concept is shown in Figure 1, which indicates The Functional Structure of Industry4.0 (Acatech, 2013).

Figure 1. The Functional Structure of Industry 4.0

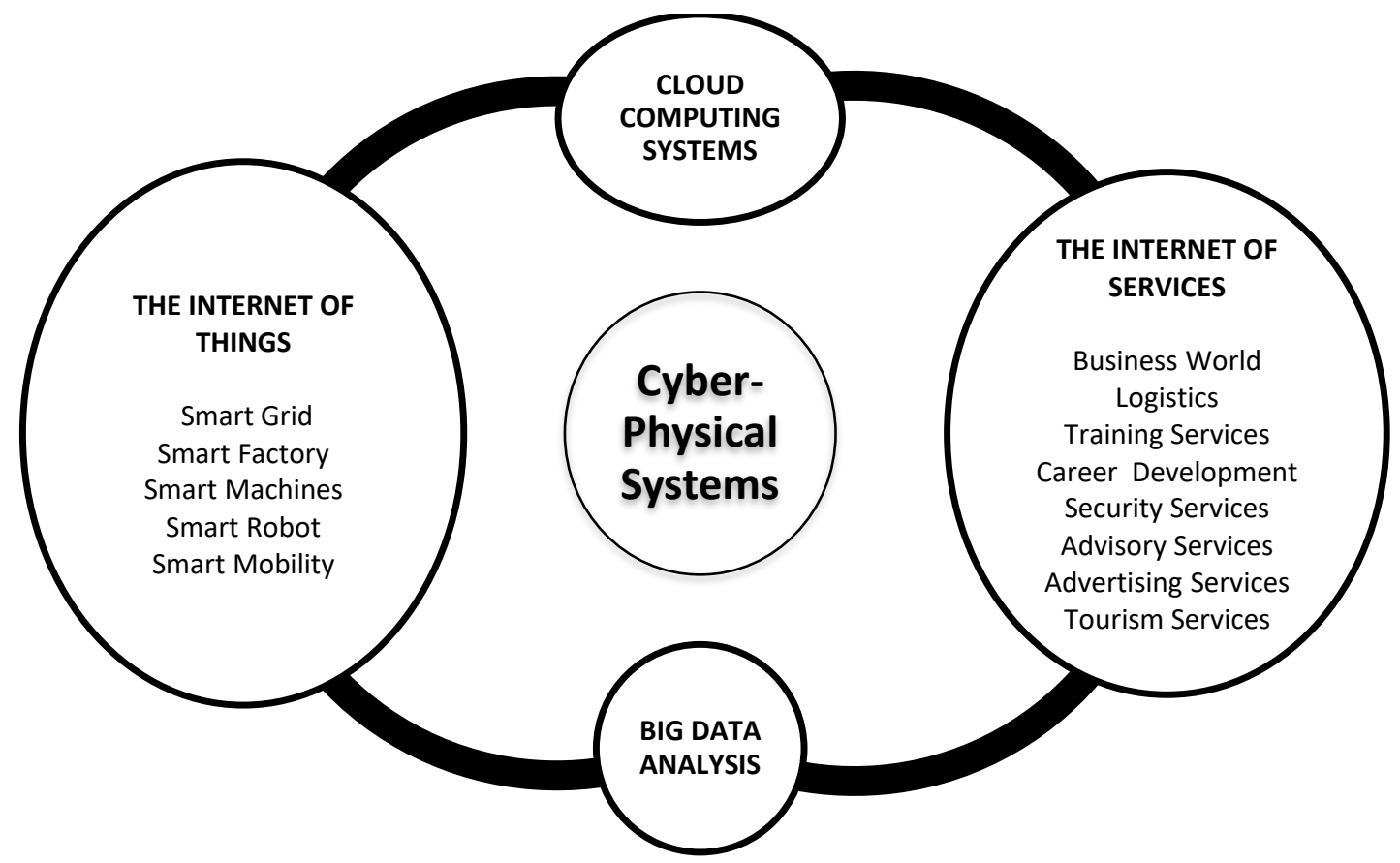

Source: Acatech (2013) National Acedemy Of Science and Engineering, Recommendations For Implementing The Strategic Initiative Industrie 4.0,Germany. April, 2013.

Conclusively, failing to take the concept of Industry 4.0 into consideration, produce projects, reorganise the structure and employees of the business, keeping up with the requirements of the time, carry out the transformation, harmonise the technological structure of the business with the future industrial revolution, and remain up to date with the required information and skills of Industry 4.0 will undoubtedly result in difficulties. These difficulties include decrease in labour demand and formation of labour constraints, emergence of reluctance in businesses that are already adapted to Industry 3.0 to upgrade their structures to Industry 4.0, conflicts between conservative businesses and shareholders, transformation costs, and, finally, the impossibility and costliness of returning to the previous condition in case of a problem (Dombrowski \& Wagner, 2014).

\section{CURRENT ADMINISTRATIONAL-ORGANISATIONAL STRUCTURES OF PRODUCTION BUSINESSES}

Administrational-organisational structures intended for collaboration among employees in order to fulfil the goals efficiently and effectively are as old as social life while the systematic data set for administrational-organisational structures in businesses started to take its place in literature only twenty centuries ago.

Therefore, for ages, the concept of administration-organisation has been considered as a form of art learned by means of trial-and-error method based on the mentor system. With the emergence of knowledge considering administration-organisation in the $20^{\text {th }}$ century, organisational charts compiled in the light of compulsory principles have started to be included in operations manuals.

As aresult of knowledge accumulation through years, the concept has evolved rapidly with the contribution of various disciplines, such as Economics, Law and Psychology, acquired a scientific aspect and, in time, been titled as scientific management (Akat, et al, 2002). Hence, 
the concept of administration-organisation consists of numerous management approaches that revolve around different viewpoints of different philosophical views, such as Scientific Management Approach, Management Process Approach, and Bureaucratic Approach (Bakan, 2004).

Subsequent to these approaches, the concept of administration-organisation was renamed as contemporary administration approach in the $20^{\text {th }}$ century. This perception has brought in a set of principles, theory, model and techniques. For instance, scientific methods employed in administration-organisation, such as Observation, Interview, Experiment, and Survey, have been employed in this approach (Şimşek, 2008).

Within the scope of contemporary administration approach, businesses have developed, transformed their structures, changed their business manners, and appropriately department a lised consequent to mechanisation following the First Industrial Revolution and electrical revolutions following the Second Industrial Revolution,. For instance, with the usage of semimechanical machines, the first process, namely, the Industrial Revolution of the $18^{\text {th }}$ century, led to the emergence of new jobs by forming areas of expertise and division of labour in accordance with the manner each machine was used. This process brought about drafting first organisational charts. During the process of the Second Industrial Revolution, the concept of assembly line was integrated into the department of production. This led to the emergence of subdivisions as the department of production was turned into a much more sophisticated business department.

Thanks to the differentiation of the revolutionary process of industry in time, employees' education levels and living standards rise, the number of experts and experienced personnel in businesses increases, groups emerge, organisational climate differs, and, hence, formal business structures are established (Can, 2002).In other words, as long as the revolutionary process continues, the need arises for diversity and growth in businesses and organisations, rules, principles, models, theories, and administrative applications to be reckoned. Thus, within the revolutionary process, the concept of Contemporary administrationorganisation can be examined in three parts; namely, Scientific Management Approach, Administrative Process Approach and Bureaucratic Approach (Can, 2002).

F. Taylor's Scientific management approach emphasizes the notion that all productive and managerial practices need to be examined with scientific methods, and that all managerial practices need to be based on scientific principles, such as efficiency and productivity. The pioneers of this approach like Taylor, Gantt, and Gilbert included scientific methods like time and motion studies especially in production processes, and regarded the issues of standard working methods, specialisation, simplicity, variety and substantiality of work, work planning and the control of the workers (Efil, 2006).

H. Fayol's Universal Principles of Management consist of the notion that the science of management operates on a number of functions, such as Management, Production, Human Resources, Marketing, Accounting and Financing, Public Relations, Research and Development, and Environment, which are all connected to certain universal principles, such as Planning, Organising, Coordinating, Controlling, and Commanding. Fayol's concept of management relies on the idea that departments form units based on concepts like similarity, complementarity, and serving the same purpose with the emphasis on division of work and expertise; the units, in turn, evolve into divisions by integrating with each other, and, ultimately, the divisions coalesce into the entity of a general administrational-organisational structure (Eren, 2003). 
Along with contributing to the accumulation of systematic information community considering management, this approach has played a significant role in the development of the science of management for generations subsequent to its application in executive training.

The organisational structure of businesses also expresses M. Weber's Bureaucratic theory. This theory includes notions like division of labour based on specialisation, hierarchy, and responsibilities, duties, rules and principles of position. This model is also used as a means of methodology in determining the degree of bureaucracy through forming the concept of ideal type (Ertürk, 2000).

Based on the question of how the ideal organisational structure should be formed, this approach briefly emphasizes an organisational structure starting from the general manager and a general coordinator in top management, continuing with the members of middle and lower management, which include department managers, section managers, branch chiefs, supervisors, craftsmen, and, at the lowest hierarchy, journeymen, respectively, in a hierarchical organisation chart. These positions are shown in Figure 2, which indicates Current Administrational-Organisational Structures of Production Businesses.

Figure 2.Current Administrational-Organisational Structures of Production Businesses

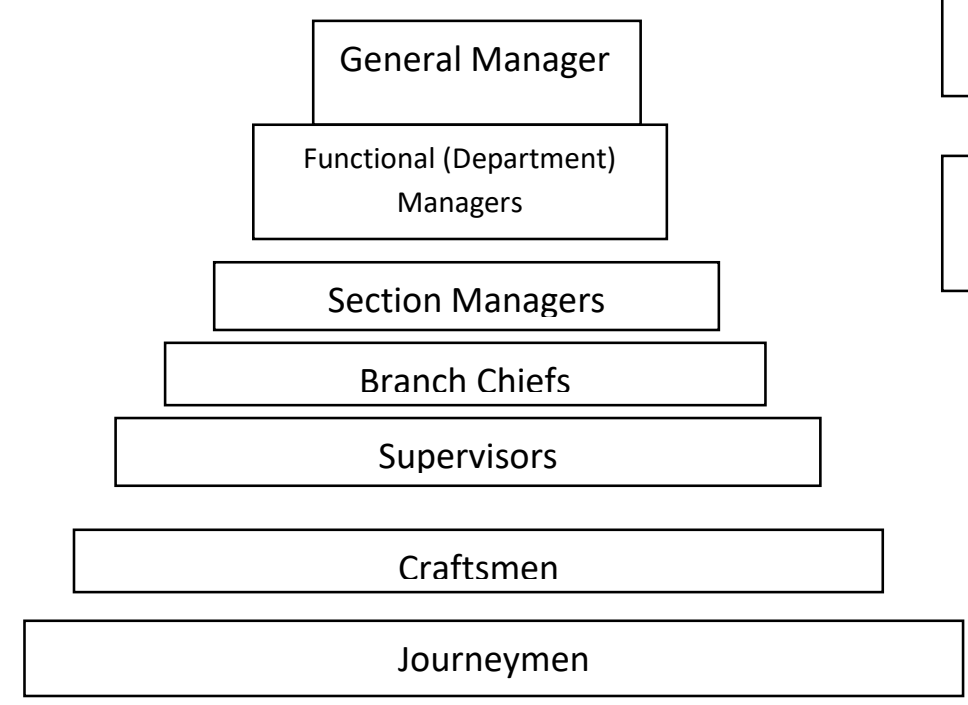

Top Management

Middle

Management

Source: Compiled by the author.

Consequently, modern administrational-organisational structure stems from Taylor's Scientific Principles of Management as indicated in his book called The Principles of Scientific Management published in 1911, Henri Fayol's Universal Principles of Management as indicated in his book Industrial and General Management published in the 1950s, and M. Weber's Bureaucratic theory.

\section{THE RESTRUCTURING OF ADMINISTRATIONAL-ORGANISATIONAL STRUCTURES OF PRODUCTION BUSINESSES IN THE PROCESS OF INDUSTRY 4.0}

The success of Industry 4.0 is closely related to the innovation capacity of business owners or managers. This innovation can be achieved either through Cyber-Physical Systems, smart production and product design, and customised production or a transformation in the structure of the supply chain (Lasi, et al., 2014). Approaches in businesses that are suitable for Industry 4.0can be formed with the concept of smart virtual organisations. This concept, in turn, can be implemented by means of qualified workers possessing appropriate knowledge and skills along with a smart virtual organisation (Van der Sluis, 2004). 
In that respect, the management approach based on Industry 4.0 is related to the businesses' management capabilities. These consist of value chain capabilities, smart factories and machines, smart production and products, the concept of customised products and services, legal restrictions, global organisational culture, product and service portfolio, market share, and access rate (Daft, 2015). These capabilities of Industry 4.0 emphasise dynamic aspects of businesses and innovative labour capabilities. Thus, businesses are able to form new management approaches by means of developing capabilities that lead to innovation (Griffin, \& Hauser, 1996).

The reorganisation of businesses is established only through innovative learning and virtual organisational climate. Taking these concepts into consideration, reorganisation can be carried out through a wide range of criteria starting from mechanical to organic design as follows: mechanical design is defined as a centralised structure, consisting of special assignments, rules and regulations, vertical communication, a hierarchical structure, and a strict authority, but it does not constitute a suitable organisational structure for the organisational culture of Industry 4.0. Conversely, organisational structure of Industry 4.0 consists of the elements of Organic design, which are decentralisation, reinforcement, flexibility of rules and regulations, horizontal (lateral) communication, and team work as this concept is more suitable for innovative learning, virtual organisational climate and digital environment (Tom \& Stalker, 1961).

Therefore, the organisational structure of Industry 4.0 should be formed through organic design, and its implementation should be carried out accordingly. With this concept, businesses can form a more flexible structure and redesign their needs and expectations in accordance with special conditions (Tom \& Stalker, 1961).

As a suitable organisational design for Industry 4.0, the implementation and practicability of this concept can occur by means of blending vertical and horizontal integration. It emphasises that all internal systems are attuned through vertical integration and all external systems are integrated through horizontal integration (Porter \& Heppelmann, 2015).

The business that restructures its administration-organisation through Organic Design can shape its reorganisation as follows: The unit consisting of assistant managers or strategists and is responsible for sustainable information supply to the top management of the business (General Coordinator) can be restructured as planning project team management and development project team management following Industry 4.0.

The duties and responsibilites of the management that is organised and formed separately as a result of the concepts like innovative information flow and smart organisational climate for next generation businesses can be explained based on the following concepts (CGI GROUP INC, 2017);

- Senior Manager,Contingency Approach, Path-Goal Theory, Innovativeness and Learning, Knowledge-based Management Structure, Transformational and Operational Style, and Innovative Role Modelling,

- Planning Team (Project Management),Estimation methods, Teamwork, Demand Estimation, Integrated Business Manager, Reliable Inventory Management, and Corporate Asset Management,

- Development team (Project Management), Product Life Cycle Management, Joint Products, Collaborative Engineering, Remote Monitoring, Remote Software Update, 3D Product Models, and Process Alert. 
Possible functions or departments of a next generation business constituted through Organic Design in the reorganisation process of Industry 4.0 can be succinctly explained by the following concepts(CGI GROUP INC, 2017);

- Digital Production Management, Operational Intelligence, Advance Process Control, Execution Systems Manufacturing, Smart Tools and Machines, Predictive Maintenance, Quality Management, Maintenance and Revision, Augmented Reality, Field Services, and Predictive Maintenance,

- E-Commerce Management (Marketing and Sales), Customer Intelligence, Promotions, Digital Marketing, E-commerce Solutions, Store Analysis, User-Consumer Experience, Secure Payment Systems and Accounting Records, Servitization, and Bartering,

- Physical Internet Management (Internal and External Logistics) Smart Products, Smart Containers, Serialisation, Just-in-Time Logistics, Supplier Cooperation, Inventory Management, Distribution Planning, and Warehouse Management,

- Digital Environment Management, the Internet of Things, the Internet of Services, Sensors, and Digital Communication,

- Energy Management, Energy Consumption Management, Low Energy Consumption, High-Quality Energy Sources, the Internet of Things, Energy Consumption Patterns, Production of Energy Consumption Sensors, Monitoring Energy Deviations, Trouble Shooting, Production Equipment Settings, Shift and Process Parameters, Predictive Analytics, Energy Planning, and Implementation of Energy Programs for Producers,

- Cloud Computing-Big Data Analysis (Information-Data Management), Access to Information, Data and Program, Distribution of Information, Data and Program, Process Control and Monitoring, Web Host Logs, Internet Statistics, Social Media Posts, Blogs and Microblogs, and Climate Sensors,

- Human Resources Management, Training, Personnel Selection, Compensation Systems, Performance Evaluation, Work Design, and Mobile Labour Management.

These concepts are compiled in Figure 3, which indicates Possible Functional Structuring of Businesses Following Industry 4.0.

Figure 3. Possible Functional Structuring of Businesses Following Industry 4.0

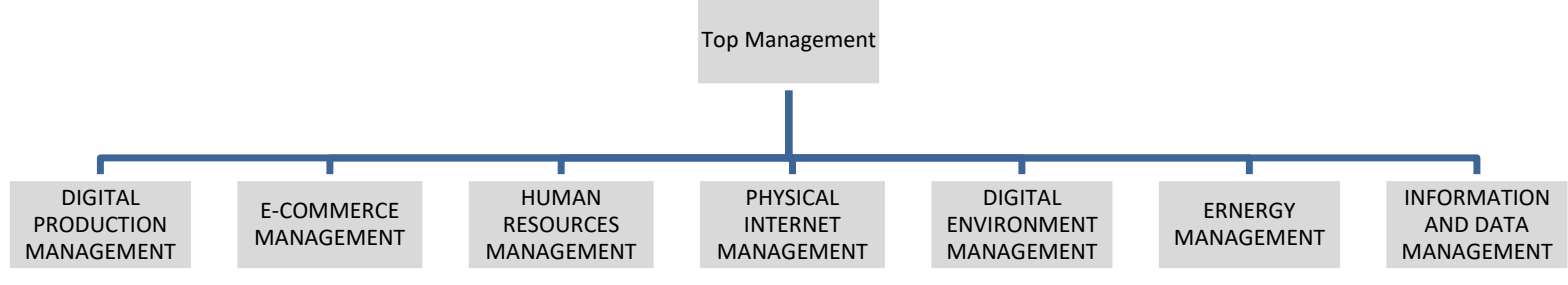

Source: Compiled by the author.

In the organisational structure renewed via Industry 4.0 , it is possible to indicate the organisational structures of next generation businesses with a matrix organisation chart by linking functions or departments that are structured through Organic Design with project teams respectively (Jones, et al., 2003).

In this structure, each employee is affiliated to two separate managements, which are project team management and functional management. Employees convey problems and solution methods to both of these managements simultaneously and introduce the solution to each problem all together. Thus, in the reorganisation of the businesses that have adopted the concept of Industry 4.0, this structure can constitute an alternative management approach as the 
positive side of the transformation, which can be observed in Figure 4, titled as Matrix Organisation Chart ( Jones, et al., 2003).

Figure 4. Matrix Organisation Chart

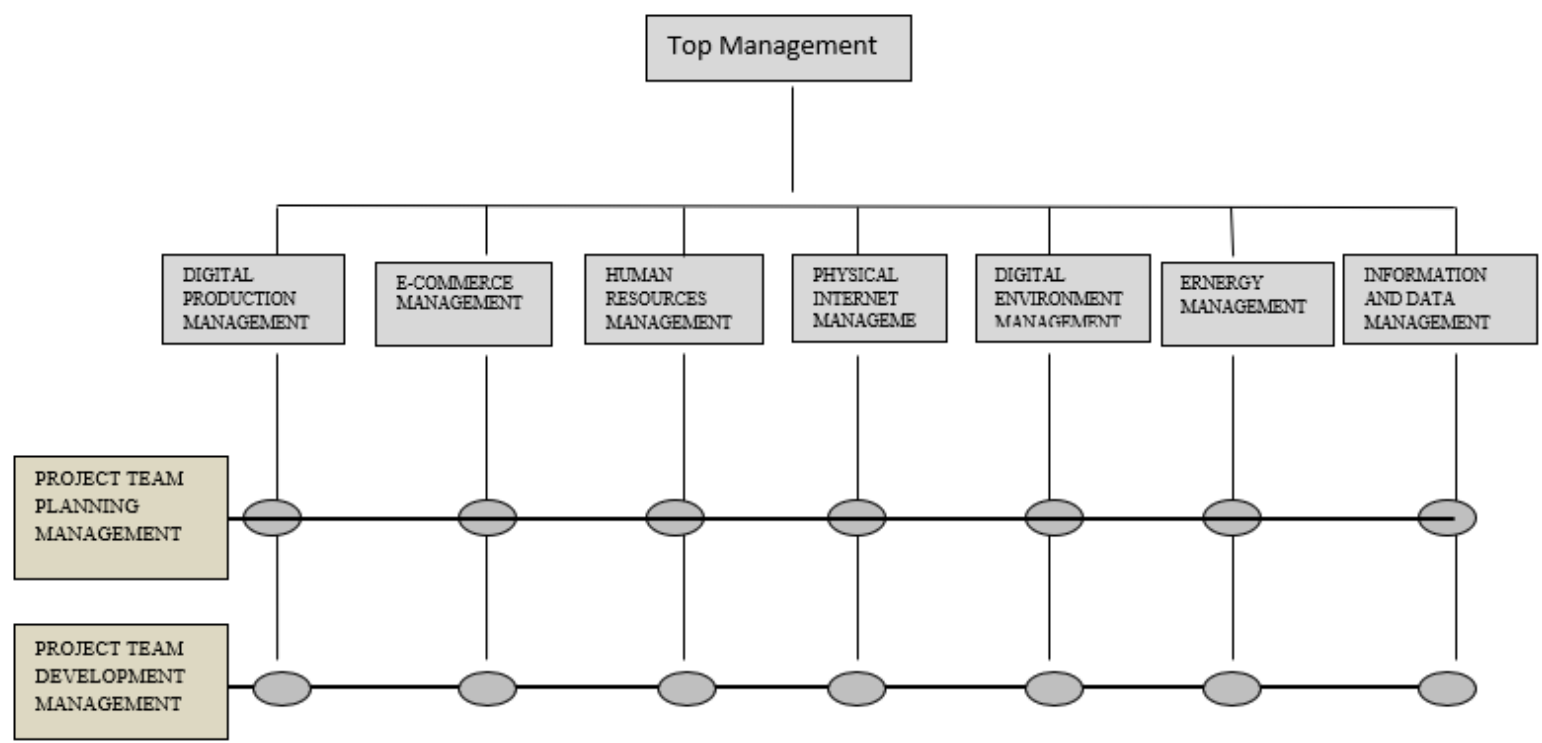

Source: Compiled by the author.

Subsequently, by adopting a new Digital environment approach, key areas can be constructed through concepts like flexible working, standardisation and reference architecture, management of complex systems, extensive infrastructure for the industry, safety and security, work organisation and design, training and career development, regulatory infrastructure, and resource efficiency. For future businesses, are newed administrational-organisational structure improved as a result of a more flexible and modular structure suitable for the abovementioned concept can be achieved by means of upgrading it in compliance with Socio-Technical Modelling (Herman, et al., 2015).

\section{CONCLUSION AND EVALUATION}

Industry 4.0 encompasses the concepts such as smart production and products, CyberPhysical Systems, Sensors, microcomputer networks, value chains, digitalisation, customised products, effective supply chains, Physical Internet for smart logistics, high value-added products and service mentality, cost advantage, and the Internet of Things and Services. Briefly, it incorporates smart production and operation activities that require innovation. Hence, the aim of the study is to find out the best management approach suitable for Industry 4.0. Namely, the study attempts to harmonise businesses' administrational-organisational structure with the concept of smart virtual organisation, emphasise the need for the discovery of the most suitable management approach regarding the survival and development of business owners and managers in the process of the Fourth Industry Revolution, which is considered as the future vision, and, finally, inform them in terms of its positive and negative impact.

The basis of the management approach suitable for Industry 4.0 lies in innovative learning and smart virtual organisation climate. Hence, innovative learning in management approach depends on the capacity of well-qualified employees' information management and learning level. Likewise, information management and innovative learning occupy a significant position in the adaptation of businesses to economic environment since this concept increases employees' abilities to be more creative and innovative. Therefore, businesses need to redesign or reorganise their existing management approaches in line with the Fourth Revolution, 
Industry 4.0. Accordingly, the notion of the most suitable management approach for Industry 4.0 hold a great significance.

In order for the harmonisation of the new management approach and Industry 4.0 to occur, the management approach suitable for Industry 4.0 should be constructed based on the concepts like smart production and products, smart factories, Cyber-Physical Systems, the Internet of Things and Services, and digitalisation. Within a suitable environment or climate, the new management approach is critical for the efficient implementation of Industry 4.0 as well as learning new skills and abilities, and overcoming challenges. Employees can enhance industrial success by means of contributing to smart production and operational activities, which are based on more creative and innovative ideas.

Industry 4.0 certainly entails the emergence of new sectors, production of smart products in smart factories without the need for manpower, gradual end of labour-intensive work with the usage of robotic technology, and the formation of qualified work force through the emergence of new jobs. Accommodating the business to Industry 4.0 occurs through harmonisation with the concept and the transformation of the processes, such as business model, automation, organisation, production and management structures, renewed training system, and the qualifications of the personnel.

Along with providing opportunities for businesses like constructing new work models, ensuring structural transformation by enabling technological structuring in terms of value creation, educating personnel in line with the new concept, and providing a renewed value chain in terms of products and processes, Industry 4.0 offers supportive opportunities regarding efficient use of business resources. Namely, Industry 4.0 introduces new job opportunities in sustainability and innovation. In order for businesses to be successful in the process of this revolution, they need to reorganise their conventional administrational-organisational structures in terms of characterisation, analysis, planning, project designs, implementation, and performance management taking into consideration the novelties of Industry 4.0, and reorganise their administrational-organisational structure with a view to encompass the visionary viewpoint of Industry 4.0 especially by means of its technological factors.

Consequently, the businesses with a suitable management approach for Industry 4.0 need to develop new skills and applications by including concepts like innovative learning, information management, construction of a smart virtual organisation climate, adaptability to the digital environment, and customised products, and harmonise their functional activities with the help of these concepts. 


\section{REFERENCES}

Acatech. (2011); Cyber-Physical Systems: Driving Force for Innovation mobility, Health, Energy and Production.Acatech(Ed.), Springer-Verlag, Berlin.

AKAT, I., BUDAK, G., BUDAK, G. (2002). Business Management, 4.b, Barış Publishing, Faculties Bookstore, Izmir.

BAKAN, I. (2004). Success Strategies for Managers, Beta Publishing, Istanbul.

BURN, T., \& STALKER, G. M. (1961). The management of innovation. London, Tavistock.

BRETTEL, M., FRIEDERICHSEN, N., KELLER, M., \& ROSENBERG, M. (2014). How virtualization, decentralization and network building change the manufacturing landscape: An industry 4.0 perspective. International Journal of Mechanical, Industrial Science and Engineering, 8(1), 37-44.

CAN, H. (2002). Organisation and Management, 6.b, Siyasal Bookstore, Ankara.

CGI GROUP INC, (2017). Industry 4.0 Making your business more competitive, https://www.cgi.com/en/white-paper/Industry-4-making-your-business-morecompetitive, Access Date: 25.11.2017.

DAFT, R. (2015). Organisation theory and design. Cengage learning.

DOMBROWSKI, U., \& WAGNER, T. (2014). Mental strain as field of action in the $4^{\text {th }}$ Industrial revolution. Procedia CIRP, 17, 100-105.

EBSO (2015); Aegean Region Chamber of Industry, "Those who donot adopt to Industry4.0 will lose", Aegean Region Chamber of Industry Journal, October, 2015.

EFIL, I. (2006). Business Management and Organisation, 6.b, Alfa Publishing, Istanbul.

EREN, E. (2003). Management and Organisation, 6.b, Beta Publishing, Istanbul.

ERTÜRK, M. (2000). Business Management and Organisation, 3.b, Beta Publishing, Istanbul.

GRIFFIN, A., \& HAUSER, J. R. (1996). Integrating R\&D and marketing: a review and analysis of the literature. Journal of Product Innovation Management, 13(3), 191-215.

HERMAN, M., PENTEK, T., \& OTTO, B. (2015). Design principles for Industry 4.0 Scenario: A literature review.

JONES, G. R., GEORGE, J.M., \& HILL, C.W. (2003). Contemporary management.New York: McGraw-Hill/Irwin.

KAGERMANN, H., HELBIG, J., HELlingER, A., \& WAHLSTER, W. (2013). Recommendations for implementing the strategic initiative INDUSTRIE 4.0: Securing the future of German manufacturing industry; final report of the Industrie 4.0 Working Group. Forschungsunion.

LANDSCHEIDT, S., \& KANS, M. (2016). Automation Practices in Wood Product Industries: Lessons learned, current Practices and Future Perspectives. In The 7th Swedish Production Symposium SPS, 25-27 October, 2016, Lund, Sweden. Lund University.

LASI, H., FETTKE, P. D. P., KEMPER, H. G., FELD, D. I. T.\& HOFFMANN, D. H. M. (2014). Industry 4.0. Business \& Information Systems Engineering, 6(4), 239-242.

LEE, J., BAGHERI, B., \& KAO, H. A. (2015). A cyber-physical systems architecture for industry 4.0-based manufacturing systems. Manufacturing Letters, 3, 18-23. 
PORTER, M. E., \& HEPPELMANN, J. E. (2015). How smart, connected products are transforming companies. Harvard Business Review, 93(10), 96-114.

ŞİMŞEK, M. Ş. (2008). Management and Organisation, 10.b, Adım Printing Press, Konya.

TOKER, E. (2016); the Scientific Journal of Industry 4.0 and the Future of Humanity, March, 2016.

TUSIAD (2016); Turkish Industrialists' and Businessmen's Association, "Industry 4.0 as a requirement for Turkey's Global Competitiveness and the Developing Economy Perspective" Publishing No: TUSIAD-T 2016-03/576 March, 2016.

VAN Der SLUIS, L. E. (2004). Designing the workplace for learning and innovation: Organizational factors affecting learning and innovation. Development and Learning in Organisations: An International Journal, 18(5), 10-13. 